\title{
Status of food intake and elemental nutrition in patients with Crohn's disease
}

\author{
Fumihito Hirai* and Toshiyuki Matsui \\ Department of Gastroenterology, Fukuoka University Chikushi Hospital, Chikushino, Fukuoka, Japan
}

\begin{abstract}
It is little known about the food intake status in patients with Crohn's disease (CD). The aim of this study was to clarify the food intake status in patients with $\mathrm{CD}$. The subjects were thirty patients with $\mathrm{CD}$ who have been followed up at our department. Food intake status per week and implementation status of elemental nutrition (EN) were investigated. 12 patients (40.0\%) were received EN more than $900 \mathrm{kcal}$ (High EN group), 5 patients (16.7\%) were received EN less than $900 \mathrm{kcal}$ (Low EN group) and 13 patients (43.4\%) did not perform EN (Non-EN group). The High EN group were more likely to take calories per day than Low EN group $(\mathrm{P}<0.0001)$ and Non-EN group $(\mathrm{P}<0.0001)$. The intake of protein and carbohydrate were significantly higher in the High EN group than in the Non-EN group $(\mathrm{P}<0.0001)$. In contrast, the intake of fat and food fiber per day was significantly lower in the High $\mathrm{EN}$ group than in the Non-EN group $(\mathrm{P}=0.0006, \mathrm{P}=0.007)$. The enforcement of $\mathrm{EN}$ in patients with $\mathrm{CD}$ is effective for maintaining good nutritional statement. As for the patients with $\mathrm{CD}$, EN should be performed for sustaining clinical remission and good nutritional status.
\end{abstract}

\section{Introduction}

Crohn's disease $(\mathrm{CD})$ is a chronic inflammatory digestive disease. The natural course of $\mathrm{CD}$ is usually progressive, disable, relapsing and most patients with $\mathrm{CD}$ receive intestinal surgery in their life $[1,2]$. Powerful therapy such as immunomodulators and anti TNFalfa antibody have possibility to change the natural course of $\mathrm{CD}$. Actually a large cohort suggest that the surgery to $C D$ recently has been reduced by effective medical treatments [3]. Immunosupressive agents are quite effective, however, these medical treatments have also potential risk of malignant disease, infection and allergic reaction [47]. Because nutrition therapy is a safe, effective therapy, it is used for the induction and maintenance therapy especially pediatric patients with CD $[8,9]$. The Japanese guideline of CD recommend nutrition therapy as maintenance therapy even for adults patients with CD [10]. Although many patients receive nutrition therapy in Japan, it is little known about the food intake status in patients with $C D$.

\section{Objective}

The aim of this study was to clarify the food intake status in patients with CD. Moreover, we investigated whether the nutrition therapy influenced on the food intake status or not.

\section{Patients and methods}

Thirty patients with CD who have been followed up at our department and agreed to the investigation about food intake were included. Patients were included regardless of the presence or absence of the nutritional therapy. The investigation was performed using the following procedure. First, patients described about all meal contents for a week from the next day of consent to the study. Second, the national registered dietitian confirmed the meal contents in detail by the interview to the patients. In this face to face interview, cooking method (oil, salt, seasoning, spice, etc) and amount of food intake using food model were confirmed. And amount of prescription and implementation status of elemental nutrition (EN) were also checked by the attending physicians. And then, calorie, three major nutrients and food fiber were calculated in detail for each participants. Moreover, we compared the contents of nutrients by means of implementation status of EN.

\section{Results}

Of the 30 subjects in this study, 12 patients $(40.0 \%)$ were received EN more than $900 \mathrm{kcal}$ (High EN group), 5 patients (16.7\%) were received EN less than $900 \mathrm{kcal}$ (Low EN group) and 13 patients (43.4\%) did not perform EN (Non-EN group) (Figure 1). According to the investigation of food intake, the High EN group were more likely to take total calorie per day than Low EN group and Non-EN group (Figure 2). The analysis of the nutrients is shown in Table 1. In the High EN group, the intake of total calorie, protein and carbohydrate were significantly higher than inthe Non-EN group $(\mathrm{P}<0.0001)$. On the other hand, intake of fat $(\mathrm{P}=0.0006)$ and food fiber $(\mathrm{P}=0.007)$ per day was significantly lower in the High EN group than in the Non-EN group.

\section{Discussion}

It is well known that diet therapy is quite important for patients with CD. However, closely long-term analysis of food intake status is not easy because people take many kinds of foods every day. In this study, the food intake status per a week of CD patients was investigated precisely as long as we could. And at the same time the implementation

Correspondence to: Fumihito Hirai, Department of Gastroenterology, Fukuoka University Chikushi Hospital, 1-1-1, Zokumyoin, Chikusino, Fukuoka 8188502, Japan, E-mail: fuhirai@cis.fukuoka-u.ac.jp

Received: March 03, 2015; Accepted: March 18, 2015; Published: March 20, 2015 
- Non-EN group Low EN group $\quad$ High EN group

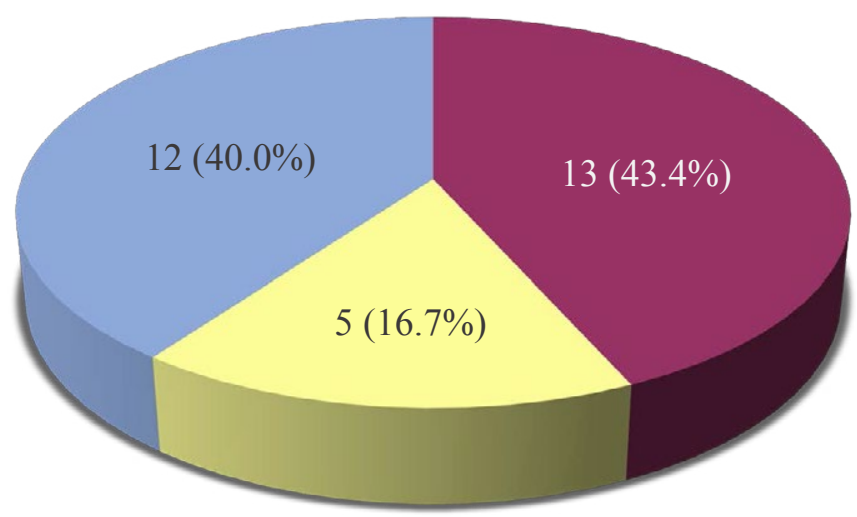

Figure 1. 12 patients (40.0\%) were received EN more than $900 \mathrm{kcal}$ (High EN group), 5 patients $(16.7 \%)$ were received EN less than $900 \mathrm{kcal}$ (Low EN group) and 13 patients (43.4\%) did not perform EN (Non-EN group).

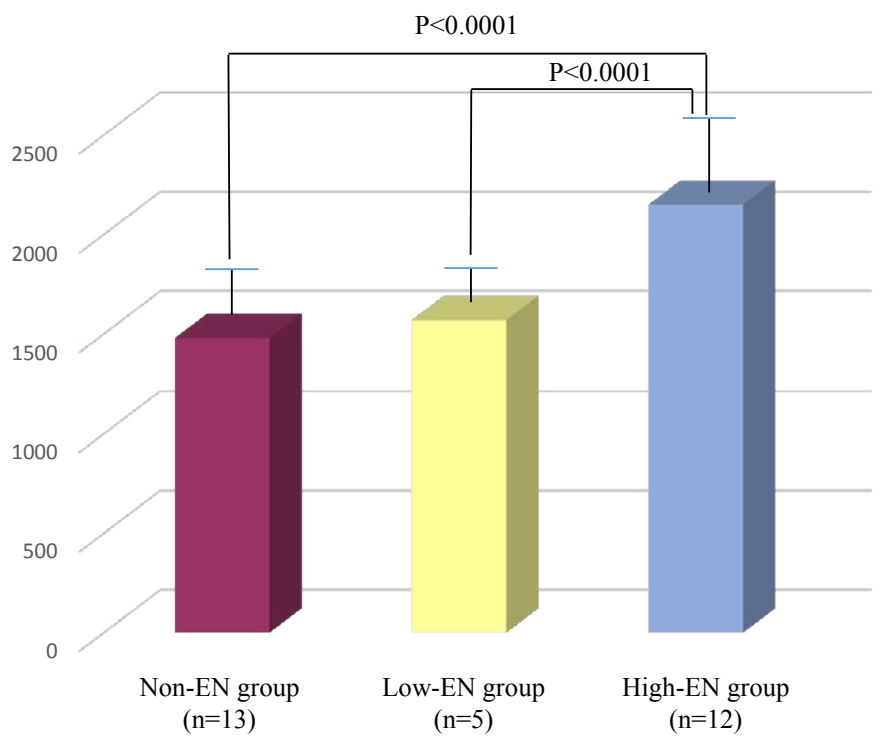

Figure 2. The total calorie per day was significantly higher in the High EN group (2148 \pm $270)$ than in the Non-EN group $(1478 \pm 151, \mathrm{P}<0.0001)$ and the Low EN group $(1574 \pm$ $71, \mathrm{P}<0.0001)$.

Table 1. Comparison of major nutrients and food fiber between Non-EN group and High EN group.

\begin{tabular}{|c|c|c|c|}
\hline & Non-EN group (n=13) & High EN group (n=12) & P-value \\
\hline Protein (g/day) & $60.0 \pm 13.7$ & $92.3 \pm 11.5$ & $\mathrm{P}<0.0001$ \\
\hline Fat (g/day) & $43.9 \pm 6.4$ & $35.1 \pm 4.4$ & $\mathrm{P}=0.0006$ \\
\hline Carbohydrate (g/day) & $196.7 \pm 16.6$ & $365.7 \pm 50.9$ & $\mathrm{P}<0.0001$ \\
\hline Fiber (g/day) & $2.2 \pm 1.0$ & $1.3 \pm 0.4$ & $\mathrm{P}=0.007$ \\
\hline
\end{tabular}

status of EN was also investigated. Patients with undergoing high mount of EN were able to take more mount of calorie per day. On the contrary, the intake of total calorie per day was insufficient in the patients who did not receive EN. There are lots of reports regarding the effectiveness of EN for CD [11-15]. The current study suggest that $\mathrm{EN}$ is also effective in terms of better nutrients intake. Additionally, the intake of fat and food fiber were lower in the High EN group than in Non-EN group in this study. Since it is generally accepted that massive intake of fat and food fiber is one of the risk of worsening in $\mathrm{CD}$ patients, this results indicate that EN has the advantage in terms of taking good nutrients.

Today, although there are several powerful medical treatments for $\mathrm{CD}$ including infliximab, concomitant $\mathrm{EN}$ is useful for maintaining remission [16]. Therefore, we do think that the enforcement of EN is desirable for $\mathrm{CD}$ patients even under receiving powerful treatments. However, several disadvantages in terms of adherence, including the taste of EN, should be resolved in order to perform long-term EN treatment.

The current study has several limitations. First, it was possibility that the small sample size have lead to the selection bias. Second, although we did not evaluate the disease activity and nutritional assessment, these factors might have influenced on the results of this study. However, we do think that the interpretation of this study regarding the status of food intake and elemental nutrition in patients with $\mathrm{CD}$ is quite helpful for the physician and co-medical stuff in real clinical practice.

\section{Conclusions}

The enforcement of EN in patients with $\mathrm{CD}$ is effective for maintaining good nutritional statement. EN should be performed not only to sustain clinical response but also to keep better nutrients intake.

\section{References}

1. Harper PH, Fazio VW, Lavery IC, Jagelman DG, Weakley FL, et al. (1987) The longterm outcome in Crohn's disease. Dis Colon Rectum 30: 174-179. [Crossref]

2. 2.Munkholm P, Langholz E, Davidsen M,Binder V, et al. (1995) Disease activity courses in a regional cohort of Crohn's disease patients. Scand J Gastroenterol 30: 699-706. [Crossref]

3. Rungoe C, Langholz E, Andersson M, Basit S, Nielsen NM, et al. (2014) Changes in medical treatment and surgery rates in inflammatory bowel disease: a nationwide cohort study 1979-2011. Gut 63: 1607-1616. [Crossref]

4. Lichtenstein GR, Feagan BG, Cohen RD, Salzberg BA, Diamond RH, et al. (2006) Serious infections and mortality in association with therapies for Crohn's disease: TREAT registry. Clin Gastroenterol Hepatol 4: 621-630. [Crossref]

5. Siegel CA, Sands BE (2005) Review article: practical management of inflammatory bowel disease patients taking immunomodulators. Aliment Pharmacol Ther 22: 1-16. [Crossref]

6. Beaugerie L, Brousse N, Bouvier AM, Colombel JF, Lémann M, et al. (2009) Lymphoproliferative disorders in patients receiving thiopurines for inflammatory bowel disease: a prospective observational cohort study. Lancet 374: 1617-1625. [Crossref]

7. Toruner M, Loftus EV Jr, Harmsen WS, Zinsmeister AR, Orenstein R, et al. (2008) Risk factors for opportunistic infections in patients with inflammatory bowel disease. Gastroenterology 134: 929-936. [Crossref]

8. 8.Dziechciarz P, Horvath A, Shamir R, Szajewska H. (2007) Meta-analysis: entera nutrition in active Crohn's disease in children. Aliment Pharmacol Ther 26: 795-806. [Crossref]

9. Van Assche G, Dignass A, Reinisch W, van der Woude CJ, Sturm A, et al. (2010) The second European evidence-based Consensus on the diagnosis and management of Crohn's disease: Special situations. J Crohns Colitis 4: 63-101. [Crossref]

10. 10.Ueno F, Matsui T, Matsumoto T, Matsuoka K, Watanabe M, et al. (2013) Evidencebased clinical practice guidelines for Crohn's disease, integrated with formal consensus of experts in Japan. J Gastroenterol 48: 31-72. [Crossref]

11. 11.Fernandez-Banares F, Cabre E, Esteve-Comas M, Gassull MA (1995) How effective is enteral nutrition in inducing clinical remission in active Crohn's disease? A metaanalysis of the randomized clinical trials. JPEN J Parenter Enteral Nutr 19: 356-364. [Crossref]

12. Okada M, Yao T, Yamamoto T, Takenaka K, Imamura K, Maeda K, et al. (1990) Controlled trial comparing an elemental diet with prednisolone in the treatment of active Crohn's disease. Hepatogastroenterology 37: 72-80. [Crossref] 
13. Takagi S, Utsunomiya K, Kuriyama S, Yokoyama H, Takahashi S, et al. (2006) Effectiveness of an 'half elemental diet' as maintenance therapy for Crohn's disease: a randomized-controlled trial. Aliment Pharmacol Ther 24:1333-1340. [Crossref]

14. O'Moráin C, Segal AW, Levi AJ. (1984) Elemental diet as primary treatment of acute Crohn's disease: a controlled trial. Br Med J (Clin Res Ed) 288: 1859-1862. [Crossref]
15. Lindor KD, Fleming CR, Burnes JU, Nelson JK, Ilstrup DM (1992) A randomized prospective trial comparing a defined formula diet, corticosteroids, and a defined formula diet plus corticosteroids in active Crohn's disease. Mayo Clin Proc 67: 328333. [Crossref]

16. Hirai F, Ishihara H, Yada S, Esaki M, Ohwan T, et al. (2013) Effectiveness of concomitant enteral nutrition therapy and infliximab for maintenance treatment of Crohn's disease in adults. Dig Dis Sci 58: 1329-1334. [Crossref]

Copyright: $(2015$ Hirai F. This is an open-access article distributed under the terms of the Creative Commons Attribution License, which permits unrestricted use, distribution, and reproduction in any medium, provided the original author and source are credited. 